\title{
CDYNAMIC CHANGE CHARACTERISTICS OF ECOSYSTEM FLUXES IN COLD ZONE WETLANDS IN NORTHEAST CHINA
}

\author{
WEI, H. ${ }^{1,2}-$ ZHANG, J., ${ }^{1,2}$ WANG, F. ${ }^{1,2^{*}}$ \\ ${ }^{I}$ North China University of Water Resources and Electric Power, Zhengzhou 450045, China \\ ${ }^{2}$ Collaborative Innovation Center of Water Resources Efficient Utilization and Support \\ Engineering, Zhengzhou 450045, China \\ *Corresponding author \\ e-mail: wangfuqiang@ncwu.edu.cn; phone/fax: +86-0371-6912-7399
}

(Received 27 $7^{\text {th }}$ Sep 2018; accepted $16^{\text {th }}$ Jul 2019)

\begin{abstract}
In order to promote the understanding of the dynamic change characteristics of ecosystem flux in cold zone wetlands and to provide scientific basis for the accurate simulation of wetland flux, this study applied the eddy covariance (EC) flux measurement system for long-term continuous flux of Harbin Jinhewan Wetland Botanical Garden. A preliminary analysis of one-and-a-half-year measurements of water, heat, and $\mathrm{CO}_{2}$ fluxes showed that: (1) The diurnal variation of $\mathrm{CO}_{2}$ flux shows a single-valley character, and the annual variation is consistent with the vegetation growth trend; the diurnal variation of $\mathrm{CO}_{2}$ concentration shows a single-peak and single-valley character, the annual change process is opposite to the vegetation growth trend. (2) The average daily $\mathrm{CO}_{2}$ absorption rate of Jinhewan Wetland is only $0.13 \mathrm{mg} /\left(\mathrm{m}^{2} \cdot \mathrm{s}\right)$, with weak carbon sink function and great carbon sequestration potential. (3) The diurnal variations of sensible heat flux (SHF), latent heat flux (LHF) and Bowen ratio (except for winter) of Jinhewan Wetland are basically single-peaked; SHF is highest in spring and LHF is highest in summer; LHF is only smaller than SHF in winter, while in summer LHF is much larger than SHF and minimum is two times that of SHF.
\end{abstract}

Keywords: Eddy covariance, sensible heat flux, latent heat flux, carbon dioxide flux, Bowen ratio

\section{Introduction}

The exchange of mass and energy in the Soil-Plant-Atmosphere Continuum (SAPC system) plays an important role in global climate, environmental change, and hydrological and ecological processes (Chen et al., 2016; Wang, 1999). The mass exchange of water and $\mathrm{CO}_{2}$ is the carrier for the biosphere to acquire and store energy, which is mainly achieved through the photosynthesis and transpiration of crops. $\mathrm{CO}_{2}$ concentration also significantly affects the earth temperature. Heat exchange plays an important role in atmospheric movement, which affects the formation of weather and climate on a larger spatial scale (Wang et al., 2013). Observing and studying the relationship among ground-air water, heat and $\mathrm{CO}_{2}$ exchange is of great significance to water cycle analysis, water resources management, and weather and climate forecast (Zheng, 2013). Since the 1980s, long-term observations of the fluxes have attracted extensive attention (Baldocchi et al., 2001).

The measurement methods for water, heat and $\mathrm{CO}_{2}$ fluxes include Eddy Covariance (EC for short), BREB method (Bowen Ratio-Energy Balance, BREB for short), aerodynamic method, and profile gradient iterative method (Liu and Yu, 1997; Shen et al., 2005; Wang et al., 2009). Among them, the EC technique uses the sensor's measurement result of the wind speed fluctuation and a certain physical quantity pulsation in the atmosphere, and the fluxes of various substances and energy are obtained by calculating the covariance between them (Roland, 1991). This technique is simple, easy, and can be directly observed (Xu et al., 2008). With the rapid development 
of measuring instruments and computing technology, the EC technique has been widely used in field observations (Liu et al., 2006), and it has achieved continuous, long-term, automatic observation of surface fluxes, while exerting minimal interference on the environment and ecosystems (Baldocchi, 2003). At present, the EC technique has become a standard method for measuring water, heat, and $\mathrm{CO}_{2}$ fluxes, and is widely used for measurement of water, heat, and carbon fluxes between the earth's surface and atmosphere (Hutley et al., 2005; Kang et al., 2001). Many factors such as undulating terrain, unfavorable weather conditions will affect the accuracy of flux measurement results by using EC technique (Massman and Lee, 2002), and to some extent hinder the application of the technique. However, the study area is flat and the elevation difference is only $5 \mathrm{~m}$. During the monitoring period, the temperature in the study area was between -30 and $30{ }^{\circ} \mathrm{C}$, and the daily precipitation was within $21 \mathrm{~mm}$ (moderate rain), except for the two maximum days of $54 \mathrm{~mm}$ (storm) and $28 \mathrm{~mm}$ (heavy rain), with no adverse weather such as extreme temperatures and precipitation. Therefore, the effects of topography and climate can be ignored in this study.

Among the currently known terrestrial ecosystems, wetland, as one of the three largest ecosystems (land, sea, and wetland), is the second most important carbon stock next to the forest. Although accounting for only $6 \%$ of the land area (Gao et al., 2008), wetland stores $10 \%-30 \%$ of the carbon of the global terrestrial ecosystem (Nahlik and Fennessy, 2016; Smith et al., 2004; Edwards, 2001). At present, there is no conclusion on the carbon source/carbon sink function of wetlands (Shoemaker et al., 2015; Duman and Schäfer, 2018). The estuarine wetland of the Niuesi River in southern Texas has carbon sink characteristics under sufficient water conditions, but it appears carbon source characteristics when there is insufficient moisture (Heinsch et al., 2004). Affected by the wetland age, geographical location, climate and other environmental conditions, the wetland ecosystem will present a carbon source or carbon sink function accordingly (Kayranli et al., 2010). In addition, when the rate of methane released by sediments exceeds the rate of carbon sequestration in the plant photosynthesis, even reed wetlands with vigorous growth of vegetation will become carbon sources (Brix et al., 2001). The absorption of $\mathrm{CO}_{2}$ in the Zoige wetland in southwestern China in 2008 and 2009 was $173 \mathrm{~g} / \mathrm{m}^{2} / \mathrm{a}$ and $292 \mathrm{~g} / \mathrm{m}^{2} / \mathrm{a}$ (Hao et al., 2001), respectively, and played a significant carbon sink function. Affected by tides, the Yangtze River estuary wetland alternates with the function of carbon sources and carbon sinks (Guo et al., 2009). In the alpine wetland ecosystem of the Tibetan Plateau, carbon absorption mainly occurred during the growing and withering stages of vegetation, while carbon release by respiration occurred during non-growing stage of vegetation (Cao et al., 2017). However, in the cold regions of northeastern China, long-term observations of wetland ecosystem fluxes are few (Chen, 1996; Yang and Lyu, 1999) and their research is not deep (He et al., 2006).

Jinhewan Wetland Botanical Garden is a demonstration area for the protection and restoration of aquatic ecosystems in Harbin, and is an important part of the ecological project of the "Hectares of Songjiang Wetland and Long-stretching Ecological Corridor". The water-heat cycle and the carbon source/carbon sink function of the wetland have an important effect on the protection and restoration of the ecosystem. This study used the EC flux measurement system to conduct long-term continuous observations of water, heat, and $\mathrm{CO}_{2}$ fluxes at Jinhewan Wetland, and characteristics of changes in water, heat and $\mathrm{CO}_{2}$ fluxes in the wetland was analyzed by using the monitoring results for one and a half year from August 1, 2015 to December 31, 2016. 
And then the characteristics of the water-heat cycle and the carbon source/carbon sink function are further analyzed, thus providing technical support for the protection and restoration of the ecosystem in the demonstration area.

\section{Test area and instrument}

\section{Test area}

The test area is located in Jinhewan Wetland Botanical Garden, Harbin, Heilongjiang

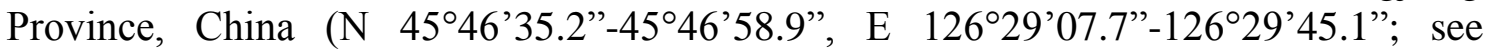
Fig. 1). Located on the left bank of the main urban area of Harbin, Songhua River, on the beach between the West Fourth Ring Bridge and the East Third Ring Bridge, it is $3,800 \mathrm{~m}$ in length, $1500 \mathrm{~m}$ in width, $3.5 \mathrm{~km}^{2}$ in area, and $115 \mathrm{~m}-120 \mathrm{~m}$ in altitude. The extremely gentle terrain effectively avoids the influence of topographic relief on the accuracy of flux observations by using EC technique.

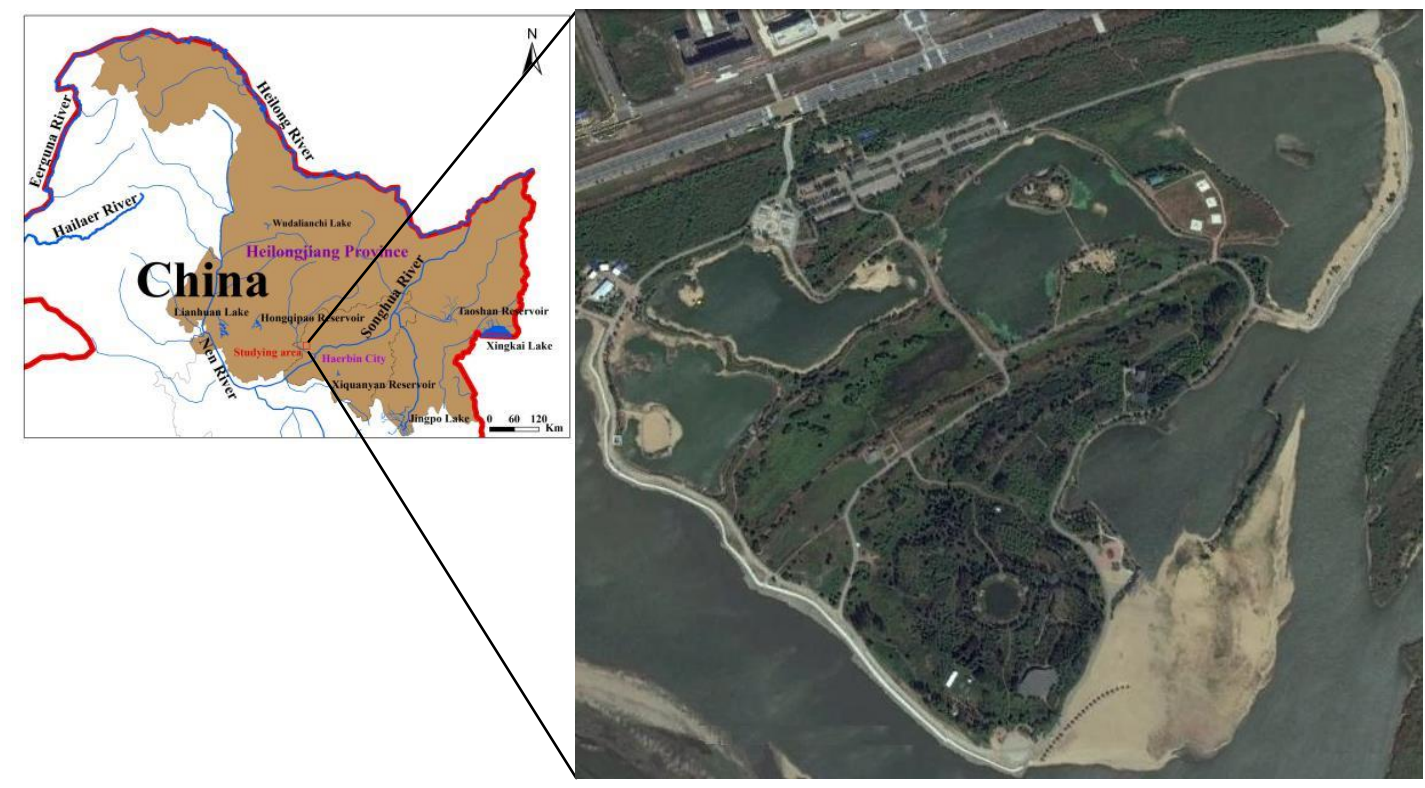

Figure 1. Harbin Jinhewan Wetland Botanical Garden

The test area is located in the middle temperate zone, which features a semi-humid continental monsoon climate with four distinct seasons, short winters and long summers. According to the meteorological data from 1951 to 2013, the average annual sunlight duration is $2636.3 \mathrm{~h}$, and the annual sunlight rate is $55-66 \%$. The average annual temperature is $3.2{ }^{\circ} \mathrm{C}$, January is the coldest month, the average monthly temperature is $-19.7^{\circ} \mathrm{C}$, and the extremely low temperature is $-41.1^{\circ} \mathrm{C}$; in the hottest month in July, the average monthly temperature is $23.1{ }^{\circ} \mathrm{C}$, and the extremely high temperature is $39.1{ }^{\circ} \mathrm{C}$. The frost-free period averages 135 days. The average annual precipitation in Harbin City where the test area is located is $570 \mathrm{~mm}$, and the maximum annual precipitation is $1015 \mathrm{~mm}$. Affected by the alternating of southeast ocean air mass and the northwest continental air mass, the distribution of rainfall season is uneven. The average annual precipitation in June-September is $341.5 \mathrm{~mm}$, accounting for about $60 \%$ of the whole year. Rainstorms are mostly concentrated in July and August, accounting 
for about $84 \%$ of the year's heavy rain. The largest rainfall in history is $146.5 \mathrm{~mm}$ (July $28,1914)$. The experimental area is surrounded by grasslands and pagoda wetland plants.

\section{Data acquisition and processing}

The EC technique can directly measure the water, heat, and $\mathrm{CO}_{2}$ fluxes (Baldocchi et al., 2000) between the atmosphere and the earth's surface in the atmospheric boundary layer, of which the basic principle is to use atmospheric turbulence theory to collect $\mathrm{CO}_{2}$ concentration, water vapor content, temperature, horizontal wind speed and vertical wind speed, and then to determine the $\mathrm{CO}_{2}$ and water and heat fluxes between the surface and the atmosphere via statistical analysis of the data. The specific analysis process (Wang, 2012) is: within a certain average period, the turbulent transport flux of a scalar $\mathrm{x}$ is described by Equation 1:

$$
Q_{x}=\overline{w(\rho x)}=\rho \overline{w x}
$$

where the over-line indicates the time average; $w$ is the vertical wind speed $(\mathrm{m} / \mathrm{s}) ; \rho$ is the air density $\left(\mathrm{kg} / \mathrm{m}^{3}\right)$, which is generally set to be constant within the average time period taken. Through Reynolds decomposition, each quantity is divided into two parts: average volume and pulse volume, as described in Equations 2 and 3:

$$
\begin{gathered}
w=\bar{w}+w^{\prime} \\
x=\bar{x}+x^{\prime}
\end{gathered}
$$

Supposing that the time average of vertical wind speed is 0 , that is, $\bar{W}=0$

$$
Q_{x}=\rho \bar{w} \bar{x}+\rho \overline{w^{\prime} x^{*}}=\rho \overline{w^{*} x^{*}}
$$

Then $\mathrm{CO}_{2}$ flux $\left(\mathrm{F}_{\mathrm{C}}, \mathrm{mg} \cdot \mathrm{m}^{-2} \cdot \mathrm{s}^{-1}\right)$, SHF $\left(\mathrm{H}, \mathrm{W} / \mathrm{m}^{2}\right)$ and $\mathrm{LHF}\left(\mathrm{LE}, \mathrm{W} / \mathrm{m}^{2}\right)$ can be expressed as in Equations 5, 6 and 7:

$$
\begin{gathered}
F_{C}=\rho \overline{w^{\prime} C^{\prime}} \\
H=C_{P} \rho \overline{w^{\prime} T^{\prime}} \\
L E=\lambda \rho \overline{w^{\prime} q^{\prime}}
\end{gathered}
$$

where is the $\mathrm{CO}_{2}$ concentration fluctuating value $(\mathrm{kg} / \mathrm{kg}) ; C_{P}$ is the air constant-pressure specific heat $\left(\mathrm{J} \mathrm{kg}^{-1} \cdot \mathrm{K}^{-1}\right)$, the general value is $1004.7 \mathrm{~J} \cdot \mathrm{kg}^{-1} \cdot \mathrm{K}^{-1} ; T^{\prime}$ is the ultrasonic virtual temperature fluctuation value $\left({ }^{\circ} \mathrm{C}\right) ; \lambda$ is the latent heat of evaporation $(\mathrm{J} / \mathrm{kg}) ; q$ ' is the water vapor concentration (specific humidity) fluctuating value ( $\mathrm{kg} / \mathrm{kg}) . \rho$ and $\lambda$ are respectively calculated by the following formulas:

$$
\begin{gathered}
\rho=100 \times \frac{P}{287.1 \times\left(T_{a}+273.15\right) \times(1+0.61 \times q)} \\
\lambda=\left(2.501-0.00237 \times T_{0}\right) \times 10^{6}
\end{gathered}
$$


In Equations 8 and 9, $\mathrm{P}$ indicates the atmospheric pressure $(\mathrm{hPa}) ; \mathrm{T}_{\mathrm{a}}$ indicates the temperature $\left({ }^{\circ} \mathrm{C}\right) ; \mathrm{T}_{0}$ indicates the surface temperature $\left({ }^{\circ} \mathrm{C}\right)$.

In the actual calculation, the data first needs to be corrected (Webb et al., 1980; Wilczak et al., 2001; Finnigan et al., 2003) by removing the outliers caused by environmental factors such as rain, snow, dust and unstable power supply; then by performing slope correction and frequency loss correction, ultrasonic virtual temperature (humidity effect) correction for SHF, WPL correction for LHF and $\mathrm{CO}_{2}$ fluxes (air density pulsation correction). Meanwhile, quality control and evaluation (Foken and Wichura, 1996) must also be carried out, such as whether the working status of the sensor is normal, whether the instantaneous value or the mean value is within a reasonable threshold, etc., and the similarity and stability of the final products (mainly the individual fluxes) need to be checked.

The eddy covariance (EC) flux measurement system was employed in this research, including the 3D ultrasonic anemometer-thermometer (CSAT3, Campbell Scientific Inc., USA), the fast-response infrared gas analyzer (Li-7500, LI- COR Inc., USA), and the data collector (CR5000, Campbell Scientific Inc., USA) and preprocessor (Eddy Reprocessing, or EdiRe, University of Edinburgh, UK, http://www.geos.ed.ac.uk/research/micromet/EdiRe). The measurement system was installed at the end of June in 2015, at the southwest corner in the Wetland Botanical Garden, with a location of N $45^{\circ} 46^{\prime} 40.3$ ', E $126^{\circ} 29^{\prime} 23.9^{\prime \prime}$. This measurement has an installation height of $10 \mathrm{~m}$ from the ground, with a data acquisition frequency of $10 \mathrm{~Hz}$ and a set average period of $30 \mathrm{~min}$. The main vegetation species at the measurement site are Labiatae and reed. The final data used to conduct analysis was recorded from August 1, 2015 to December 31, 2016, with a duration of one and a half years.

\section{Results}

In order to promote the understanding of the dynamic change characteristics of wetland ecosystems, we analyzed the daily changes and seasonal changes of $\mathrm{CO}_{2}$ flux, $\mathrm{CO}_{2}$ concentration, SHF, LHF and Bowen ratio (ratio of SHF to LHF) of Jinhewan Wetland based on one-and-a-half EC flux measurements.

\section{Characteristics of changes in water and heat fluxes}

\section{Characteristics of daily changes in water and heat fluxes}

January, April, July and October were selected as the representative months of the year (in which the data took the average of the data for October 2015 and October 2016) to analyze the average monthly diurnal variation of water and heat fluxes near the underlying surface ecosystem of Jinhewan Wetland in spring, summer, autumn and winter, and SHF and LHF were put in a contrastive analysis by using the Bowen ratio (the absolute value of which reflects the strong and week relationship between the sensible and latent heat exchange), as shown in Figure 2.

Sensible heat refers to the heat exchange in the form of turbulence that occurs between the atmosphere and the underlying surface due to temperature changes. Heat is positive when it is transported from the underlying surface to the atmosphere, and vice versa. The daily changes of SHF of Jinhewan Wetland throughout the year show singlepeaked features. Before 8:30 in the morning of January, SHF was always negative, which is because the surface temperature is lower than the atmosphere at night, and heat 
is transported from the atmosphere to the ground. The heat supplied to the ground is offset by the amount of radiation on the ground, making the temperature difference between surface and atmosphere stable. Therefore, the SHF floats up and down at $10 \mathrm{~W} / \mathrm{m}^{2}$. As the sun rises, solar radiation appears and gradually increases, and the ground continues to heat up, the temperature difference between the surface and the atmosphere begins to decrease and the SHF gradually becomes larger; SHF becomes positive at around 9:00, indicating that the surface temperature begins to rise above the atmosphere, and sensible heat is transferred to the atmosphere from the ground; then SHF increases rapidly and peaks at 12:00, indicating that the temperature difference between the surface and atmosphere reaches a maximum, as a result, the transport of sensible heat from the ground to the atmosphere achieves the highest rate of about $50 \mathrm{~W} / \mathrm{m}^{2}$; then the SHF decreases sharply, because the surface radiation of hightemperature surface is strong, and the solar radiation weakens again, as a result, the surface temperature drops rapidly and approaches atmospheric temperature as soon as 16:00, and the $\mathrm{SHF}$ is about $0 \mathrm{~W} / \mathrm{m}^{2}$; as ground radiation continues to cool down the earth's surface, the surface temperature begins to fall below the atmosphere, and sensible heat is transported from the atmosphere to the ground. The flux is negative, and it stabilizes after 17:00, indicating that the monthly SHF is positive for about $7 \mathrm{~h}$. Due to the difference in sun rise and fall times in different seasons, the time course of monthly SHF change in April and July was different from that in January, where SHF starts to increase slowly from a negative value at about 5:00, and becomes positive at about 6:00 when the sensible heat starts to be transported from the ground to the atmosphere; it also reaches its maximum at around 12:00, which is close to $150 \mathrm{~W} / \mathrm{m}^{2}$ and $80 \mathrm{~W} / \mathrm{m}^{2}$ respectively; SHF is reduced to $0 \mathrm{~W} / \mathrm{m}^{2}$ at $18: 00$, and maintains a stable state of small-scale fluctuations by approaching 19:00; these two representative monthly SHF takes $12 \mathrm{~h}$ to be transported from the ground to the atmosphere. The rise of SHF in October was similar to that in April and July, and the decline was in sync with January; the peak was around $90 \mathrm{~W} / \mathrm{m}^{2}$, indicating that the monthly SHF is positive for $9 \mathrm{~h}$. It can be seen that Jinhewan Wetland has the shortest SHF time in winter and the lowest peak value, while in the spring and summer, the SHF diurnal variation is more synchronous, the positive and negative flux values have the equal time. The peak value of spring flux is the highest, and the positive duration of SHF in autumn is slightly longer than in winter, and the peak value is close to summer, which is in the middle of the peak of the four seasons' flux.

Latent heat mainly refers to the heat energy absorbed or released from one phase to another by water under isothermal pressure conditions. When LHF is greater than $0 \mathrm{~W} / \mathrm{m}^{2}$, it mainly absorbs heat through soil evaporation and vegetation transpiration. When LHF is less than $0 \mathrm{~W} / \mathrm{m}^{2}$, heat is released mainly through dew, frost, and icing. The daily changes of LHF of Jinhewan Wetland in the four seasons also have a singlepeaked feature, except that the feature is not significant in January. In January, in addition to the increase in LHF from about $0 \mathrm{~W} / \mathrm{m}^{2}$ to $10 \mathrm{~W} / \mathrm{m}^{2}$ in peak value between 10:00 and 16:00, it is reduced to $0 \mathrm{~W} / \mathrm{m}^{2}$, and LHF fluctuates up and down around $0 \mathrm{~W} / \mathrm{m}^{2}$ in $3 / 4$ time of the entire day/night. In the other three representative months, LHF is greater than $0 \mathrm{~W} / \mathrm{m}^{2}$. Among them, LHF increases rapidly from 6:00 in April and October, reaching the peak $160 \mathrm{~W} / \mathrm{m}^{2}$ and $110 \mathrm{~W} / \mathrm{m}^{2}$ at 13:00, and then continues to decrease, and basically maintains between $20 \mathrm{~W} / \mathrm{m}^{2}-40 \mathrm{~W} / \mathrm{m}^{2}$ from $20: 30$. July increases from 3:30 and peaks at around $220 \mathrm{~W} / \mathrm{m}^{2}$ before 13:00, and it also begin to fluctuate around $30 \mathrm{~W} / \mathrm{m}^{2}$ at 20:30. The results show that Jinhewan Wetland not only 
transports water from the atmosphere to the ground during the night in winter, but also transports it from the ground to the atmosphere through evapotranspiration, indicating the strong water cycle characteristics of wetlands. In addition, the evapotranspiration is relatively weak in winter and is strong in spring and autumn, and during the summer daytime, due to the higher temperature, the evaporation of soil moisture can be promoted, and the vegetation also reduces its own temperature by enhancing transpiration, so the underlying surface evapotranspiration plays the most important role.
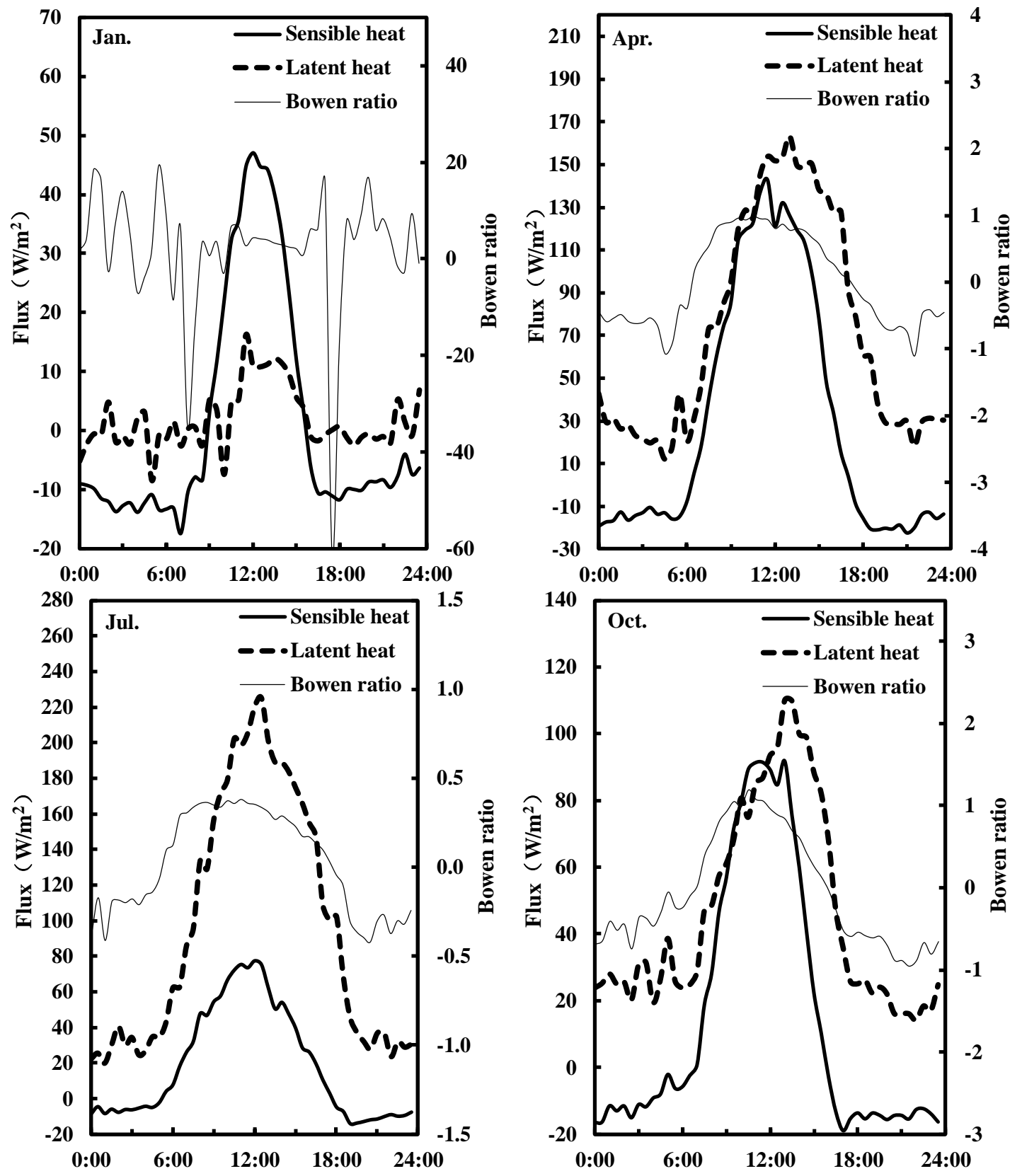

Figure 2. Diurnal variation of monthly averaged water and heat fluxes in representative months from different seasons in Jinhewan Wetland 
By analyzing the size of the Bowen ratio, the SHF and LHF at any time during the average monthly diurnal variation (without considering the energy transfer direction of the sensible heat and the latent heat, only considering the size of the flux) are compared. LHF is less than SHF only in January, and because LHF is very small and even less than $1 \mathrm{~W} / \mathrm{m}^{2}$, the fluctuation of the Bowen ratio (absolute value) in January is relatively large. Without considering extreme cases, the range of variation is 1-20. LHF is almost always greater than SHF during the monthly diurnal variation in spring, summer and autumn. Among them, in April and October, the Bowen ratio (absolute value) fluctuates in the range of 0-1 (except that LHF is slightly smaller than SHF at some time in October, and the Bowen ratio is within 1-1.1). The overall difference between LHF and SHF is relatively small. Bowen ratio (absolute value) is greater than 0.5 about $65 \%$ of the time, the two are almost equal especially between 9:00-12:00, and the Bowen ratio is above 0.92. In July, the fluctuation range of Bowen ratio (absolute value) is only $0-0.5$, and LHF is much larger than SHF.

\section{Seasonal changes in water and heat fluxes}

According to the observations of Jinhewan Wetland from August 2015 to December 2016, the daily average water and heat fluxes were calculated, and seasonal variations of water and heat fluxes were analyzed according to the annual change process. Figure $3 a$, $b$, and $c$ show the change of annual mean value of the sensible heat, latent heat, and Bowen ratio, respectively.

Over the nearly one-and-a-half-year observation period, the average daily SHF ranged from -49.97 to $90.63 \mathrm{~W} / \mathrm{m}^{2}$, and the annual average daily change was smaller (see Fig. 3a). Daily SHF averaged $13.78 \mathrm{~W} / \mathrm{m}^{2}$; in the winter (December-February), the average was the lowest, only $3.57 \mathrm{~W} / \mathrm{m}^{2}$; in the spring (March-May), the average was the highest, reaching $19.13 \mathrm{~W} / \mathrm{m}^{2}$; in the summer and autumn (June-August and SeptemberNovember, respectively), the average daily SHF average was mediate, with summer slightly higher than autumn, at $18.65 \mathrm{~W} / \mathrm{m}^{2}$, and the autumn average was close to the average during the observation period, which was $14.71 \mathrm{~W} / \mathrm{m}^{2}$.

Average daily LHF fluctuated more intensively, ranging from $-12.28 \mathrm{~W} / \mathrm{m}^{2}$ to $213.40 \mathrm{~W} / \mathrm{m}^{2}$ (see Fig. $3 b$ ). The average value over a one-year observation period was $50.27 \mathrm{~W} / \mathrm{m}^{2}$; Characteristics of daily average LHF was the same as SHF in winter, only $3.87 \mathrm{~W} / \mathrm{m}^{2}$, which is far lower than the average of the other three seasons; the summer average was as high as $91.40 \mathrm{~W} / \mathrm{m}^{2}$; average daily LHF during the spring and autumn determines the average value of the observation period, and it was always fluctuating around $50 \mathrm{~W} / \mathrm{m}^{2}$; seasonal averages were $70.88 \mathrm{~W} / \mathrm{m}^{2}$ and $42.77 \mathrm{~W} / \mathrm{m}^{2}$, respectively.

Dividing the daily average SHF by the daily average LHF, we can get the annual variation of the daily scale Bowen ratio during the observation period (see Fig. 3c). Except for the late autumn period (from November 13 to November 30 for 2015 and 2016) and winter, and due to the continuous fluctuation of the daily average LHF around $0 \mathrm{~W} / \mathrm{m}^{2}$, the Bowen ratio varied greatly and changed narrowly within -3.08-3.33 for most of the spring, summer and autumn. Bowen ratio not only varied greatly in winter, but also fluctuated drastically, with only $30 \%$ of the time ranging from -1 to 1 , indicating that the daily average SHF in winter is generally greater than the daily average LHF; while in the summer Bowen ratio ranged from -0.40 to 0.68 , the daily average LHF was not only larger than the daily average SHF, but also at least 1.47 times that of the latter; in the spring and autumn, the daily average LHF was usually greater than the daily average SHF, with $70 \%$ of the time Bowen ratio ranging from -1 to 1 . 

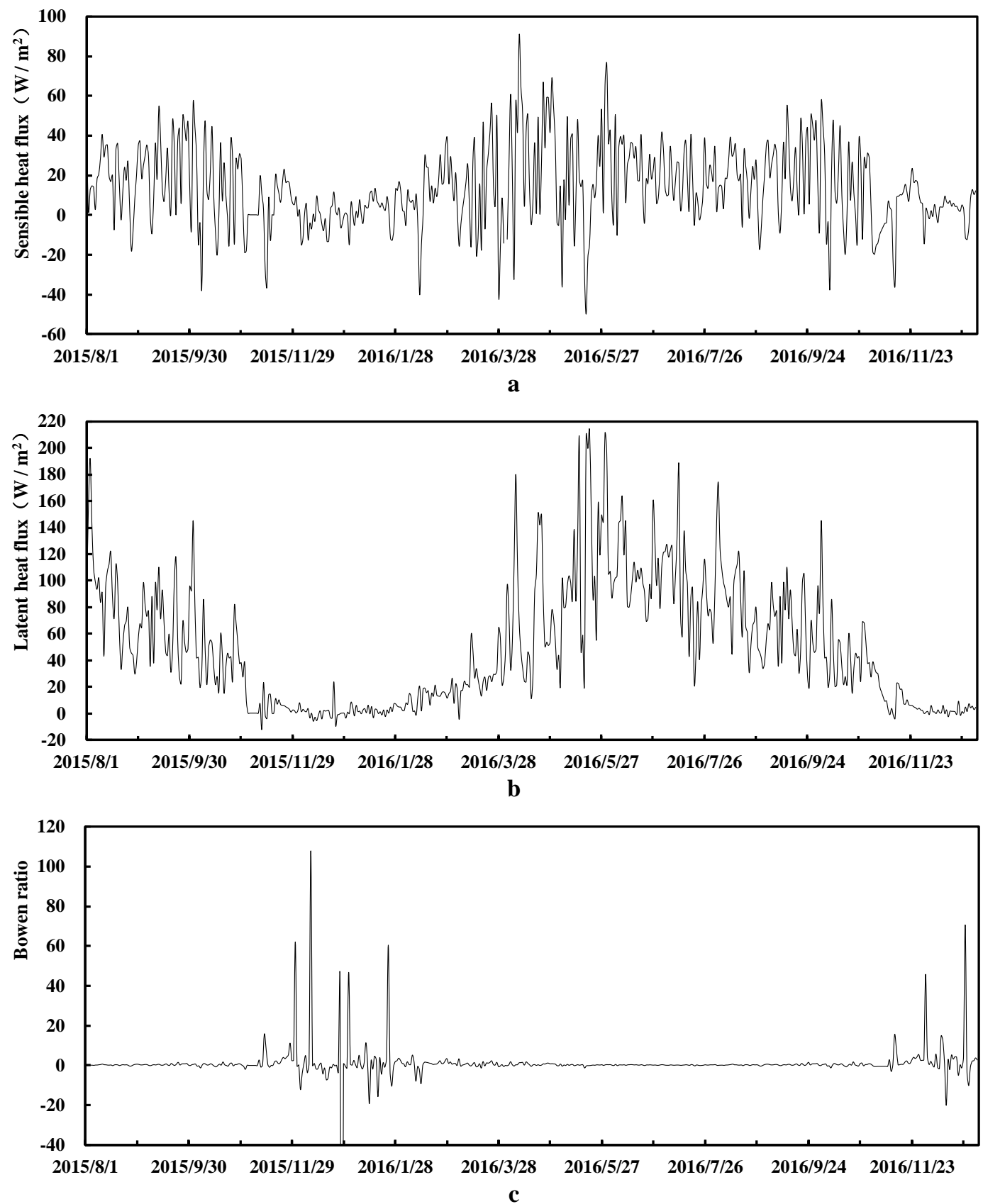

Figure 3. Annual daily average change of Jinhewan Wetland sensible heat flux (a), latent heat flux (b) and Bowen ratio (c) during August 2015-December 2016

\section{Characteristics of $\mathrm{CO}_{2}$ flux change}

Figure 4 shows the average monthly diurnal variation and the average daily diurnal variation of the Jinhewan Wetland $\mathrm{CO}_{2}$ flux in January and July. When the $\mathrm{CO}_{2}$ flux is negative, it indicates that the surface absorbs $\mathrm{CO}_{2}$ from the atmosphere due to photosynthesis and other reasons; when it is positive, it indicates that the surface releases $\mathrm{CO}_{2}$ into the atmosphere under the effects of vegetation and soil microbial respiration. As can be seen from the figure, the $\mathrm{CO}_{2}$ flux has the diurnal variation characteristics of the single-valley character. Due to the lack of sunlight at night, the 
vegetation cannot absorb $\mathrm{CO}_{2}$ via photosynthesis, instead they release $\mathrm{CO}_{2}$ through stable respiration of vegetation and soil microorganisms, therefore the nighttime $\mathrm{CO}_{2}$ flux is greater than $0 \mathrm{mg} /\left(\mathrm{m}^{2} \cdot \mathrm{s}\right)$ with little change. Jinhewan Wetland shows weak carbon source attribute, which fluctuates around $0.02 \mathrm{mg} /\left(\mathrm{m}^{2} \bullet \mathrm{s}\right)$ in January, and shows strong respiration with vigorous vitality of vegetation, and $\mathrm{CO}_{2}$ flux fluctuates around $0.10 \mathrm{mg} /\left(\mathrm{m}^{2} \cdot \mathrm{s}\right)$; average annual $\mathrm{CO}_{2}$ flux at night is about $0.05 \mathrm{mg} /\left(\mathrm{m}^{2} \cdot \mathrm{s}\right)$ and the maximum is $0.08 \mathrm{mg} /\left(\mathrm{m}^{2} \bullet \mathrm{s}\right)$. After sunrise, the vegetation begins to undergo photosynthesis, and as the sunlight increases, the photosynthesis intensity also slowly increases. The $\mathrm{CO}_{2}$ absorption rate increases from $0 \mathrm{mg} /\left(\mathrm{m}^{2} \bullet \mathrm{s}\right)$ and gradually equals the release rate, and its flux begins to decrease and approach $0 \mathrm{mg} /\left(\mathrm{m}^{2} \bullet \mathrm{s}\right)$ step by step, which drops to $0 \mathrm{mg} /\left(\mathrm{m}^{2} \bullet \mathrm{s}\right)$ before 10:00 and 5:30 in January and July, and drops to 0 $\mathrm{mg} /\left(\mathrm{m}^{2} \cdot \mathrm{s}\right)$ before $6: 30$ on an annual average. As sunlight becomes stronger, the rate of $\mathrm{CO}_{2}$ absorption by vegetation through photosynthesis is greater than the release rate, and the $\mathrm{CO}_{2}$ flux becomes negative and decreases. Jinhewan Wetland begins to play a carbon sink role; at noon time, the sunlight reaches the strongest and $\mathrm{CO}_{2}$ flux reaches the least value, which reduce to $-0.05 \mathrm{mg} /\left(\mathrm{m}^{2} \bullet \mathrm{s}\right)$ and $-0.41 \mathrm{mg} /\left(\mathrm{m}^{2} \bullet \mathrm{s}\right)$ in January and July, respectively, and the average annual minimum flux is $-0.13 \mathrm{mg} /\left(\mathrm{m}^{2} \cdot \mathrm{s}\right)$. As the sunlight weakens in the afternoon, photosynthesis is weakened and the $\mathrm{CO}_{2}$ absorption rate begins to decrease. When it is again equal to the rate of $\mathrm{CO}_{2}$ release, the flux turns to $0 \mathrm{mg} /\left(\mathrm{m}^{2} \bullet \mathrm{s}\right)$ again, reaching $0 \mathrm{mg} /\left(\mathrm{m}^{2} \bullet \mathrm{s}\right)$ after 15:00 and 18:00 in January and July, and averaging $0 \mathrm{mg} /\left(\mathrm{m}^{2} \cdot \mathrm{s}\right)$ after $17: 30$ on a yearly basis. Photosynthesis continues to weaken until it stops, and the respiration of vegetation and soil microorganisms begins to dominate. $\mathrm{CO}_{2}$ flux increases again and becomes positive after being stable. In general, Jinhewan Wetland has a carbon sink function only $5 \mathrm{~h}$ a day in winter, and the $\mathrm{CO}_{2}$ absorption rate is within $0.05 \mathrm{mg} /\left(\mathrm{m}^{2} \bullet \mathrm{s}\right)$. In summer, the carbon sink function is slightly stronger and it plays a carbon sink role for about $13 \mathrm{~h}$ per day. Absorption rate is relatively high, up to $0.41 \mathrm{mg} /\left(\mathrm{m}^{2} \bullet \mathrm{s}\right)$; the annual average carbon sink function is $11 \mathrm{~h}$ a day, and $\mathrm{CO}_{2}$ absorption rate is up to $0.13 \mathrm{mg} /\left(\mathrm{m}^{2} \cdot \mathrm{s}\right)$, less than half of the highest absorption rate of Panjin wetland $\left(0.3 \mathrm{mg} /\left(\mathrm{m}^{2} \bullet \mathrm{s}\right)\right.$ (Wang and Zhou, 2006) that has the reputation of "the capital of wetlands".

To analyze the seasonal variation characteristics of $\mathrm{CO}_{2}$ flux, $\mathrm{CO}_{2}$ flux data with a time step of 30 min was taken for a $6 \mathrm{~h}$ sliding average treatment (as shown in Fig. 5). In the non-growing season of vegetation (from late autumn to early spring, approximately from November to March of the following year), $\mathrm{CO}_{2}$ flux (absolute value) was small and it was greater than 0 in most of the time, indicating that vegetation photosynthesis was weak or even absent from photosynthesis during this period, atmospheric carbon exchange process is achieved mainly through vegetation and soil respiration. In the growing season of vegetation, the amplitude of $\mathrm{CO}_{2}$ flux increased. In particular, during vigorous growth periods (July and August), vegetation has the most intense life activities: intense photosynthesis during the day brings rapid absorption of $\mathrm{CO}_{2}$ and a large negative value of $\mathrm{CO}_{2}$ flux; at night, vegetation respiration was also strong, and the release rate of $\mathrm{CO}_{2}$ was also large. Regardless of whether $\mathrm{CO}_{2}$ is transported from the atmosphere to the surface during the day or when $\mathrm{CO}_{2}$ is transported from the surface to the atmosphere at night, the $\mathrm{CO}_{2}$ flux during the vigorous growth of vegetation is higher than at the initial stage of growth (April to June) or at the end of growth (September and October), while the $\mathrm{CO}_{2}$ flux in the growing season was higher than that in the non-growing season, and the change pattern of the year coincided with the vegetation growth trend. 


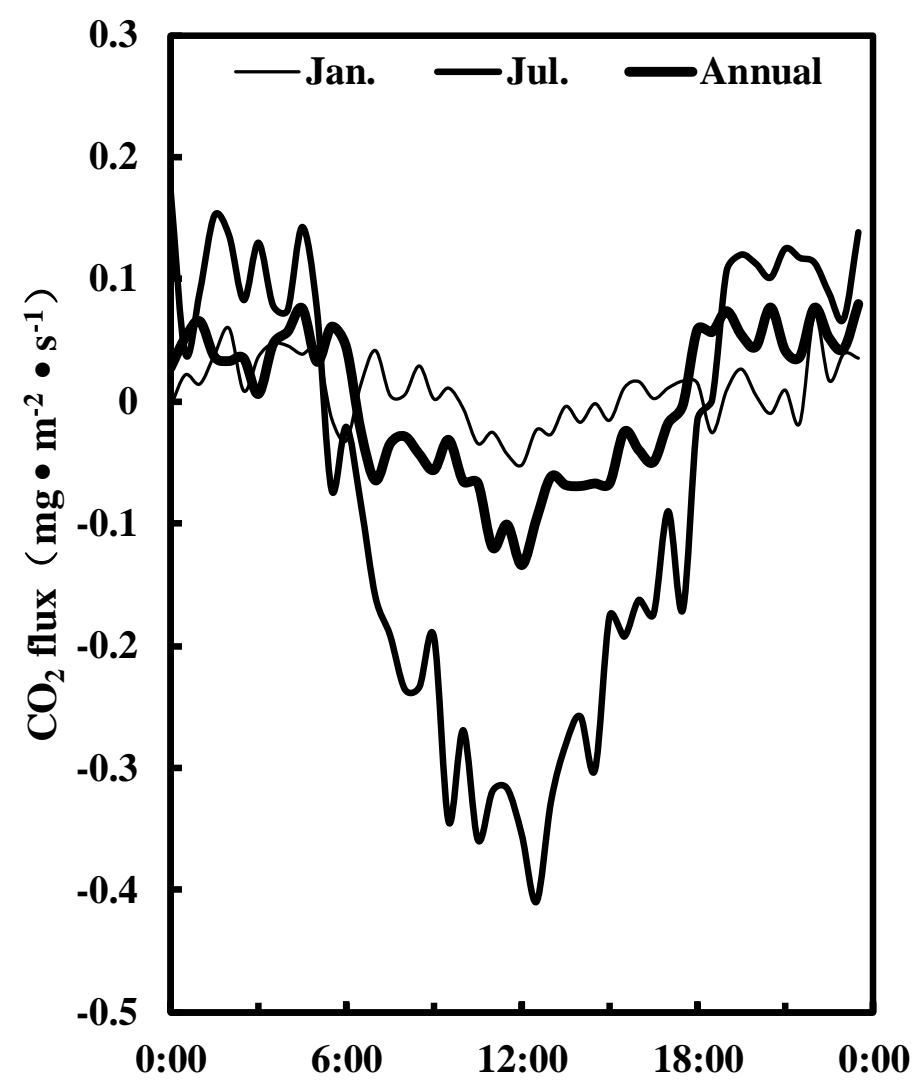

Figure 4. Diurnal variation of monthly and yearly averaged $\mathrm{CO}_{2}$ flux in Jinhewan Wetland

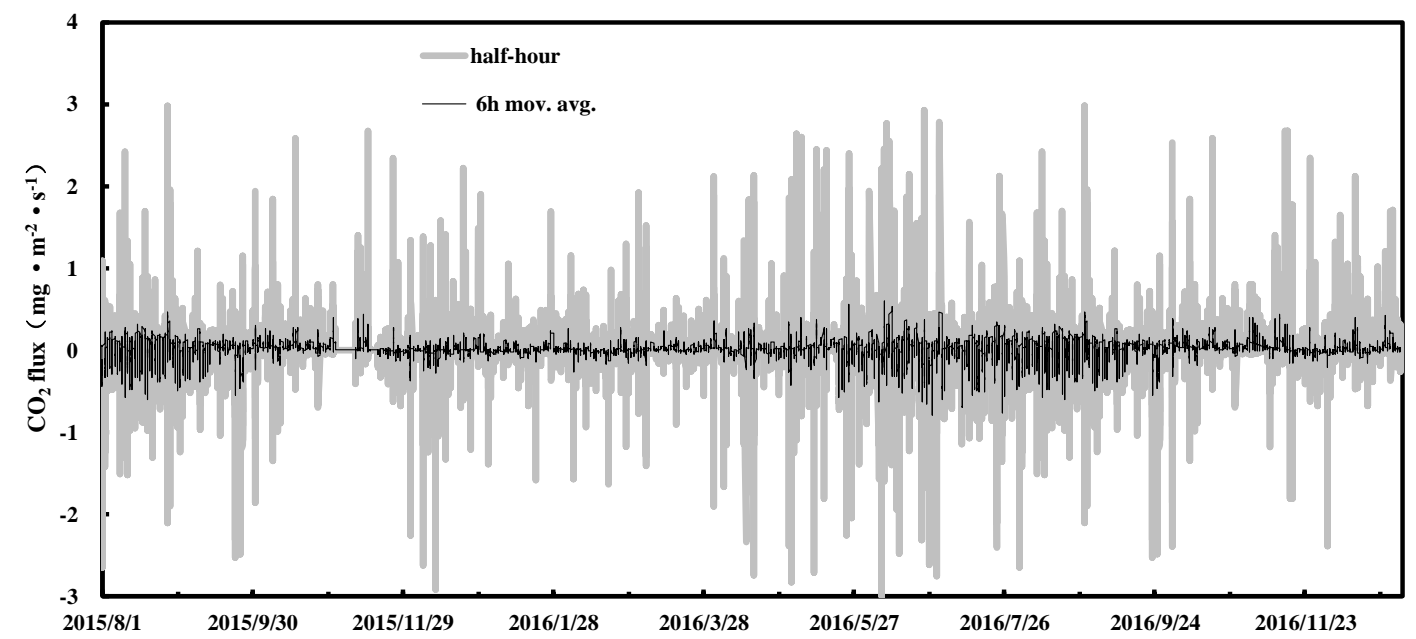

Figure 5. Annual change process of Jinhewan Wetland $\mathrm{CO}_{2}$ flux during August 2015-December 2016

\section{Characteristics of $\mathrm{CO}_{2}$ concentration changes}

The average monthly diurnal variation of the Jinhewan Wetland $\mathrm{CO}_{2}$ concentration in January and July showed a single-peak and single-valley character (see Fig. 6). As a carbon source, the $\mathrm{CO}_{2}$ flux of Jinhewan Wetland at night was always greater than $0 \mathrm{mg} /\left(\mathrm{m}^{2} \bullet \mathrm{s}\right)$, and near-surface $\mathrm{CO}_{2}$ concentrations continued to accumulate, showing an 
upward trend. After sunrise, with the $\mathrm{CO}_{2}$ absorption from the photosynthesis of vegetation, when the $\mathrm{CO}_{2}$ flux approaches $0 \mathrm{mg} /\left(\mathrm{m}^{2} \cdot \mathrm{s}\right)$, the concentration peaks: reaching $720 \mathrm{mg} / \mathrm{m}^{3}$ at $8: 00$ in January, and $670 \mathrm{mg} / \mathrm{m}^{3}$ at $4: 30$ in July, with an annual average peak value of $700 \mathrm{mg} / \mathrm{m}^{3}$. As the $\mathrm{CO}_{2}$ flux became negative, the wetland began to function as a carbon sink and the $\mathrm{CO}_{2}$ concentration began to decrease. When the $\mathrm{CO}_{2}$ flux increased to $0 \mathrm{mg} /\left(\mathrm{m}^{2} \bullet \mathrm{s}\right)$ due to the weakening of sunlight, the $\mathrm{CO}_{2}$ concentration dropped to the bottom: reaching $670 \mathrm{mg} / \mathrm{m}^{3}$ and $590 \mathrm{mg} / \mathrm{m}^{3}$ around $16: 00$ in January and July, with an annual average of $650 \mathrm{mg} / \mathrm{m}^{3}$. Then the $\mathrm{CO}_{2}$ flux became positive and remained stable, so the concentration began to rise again. The difference between the peak value and bottom value of $\mathrm{CO}_{2}$ concentration in July was greater than that in January, indicating that the photosynthesis and respiration of vegetation in summer had greater impact on $\mathrm{CO}_{2}$ concentration than in winter. In summer, not only photosynthesis was strong from the strong sunlight, but vegetation was also in the growing season, with strong vitality and respiration.

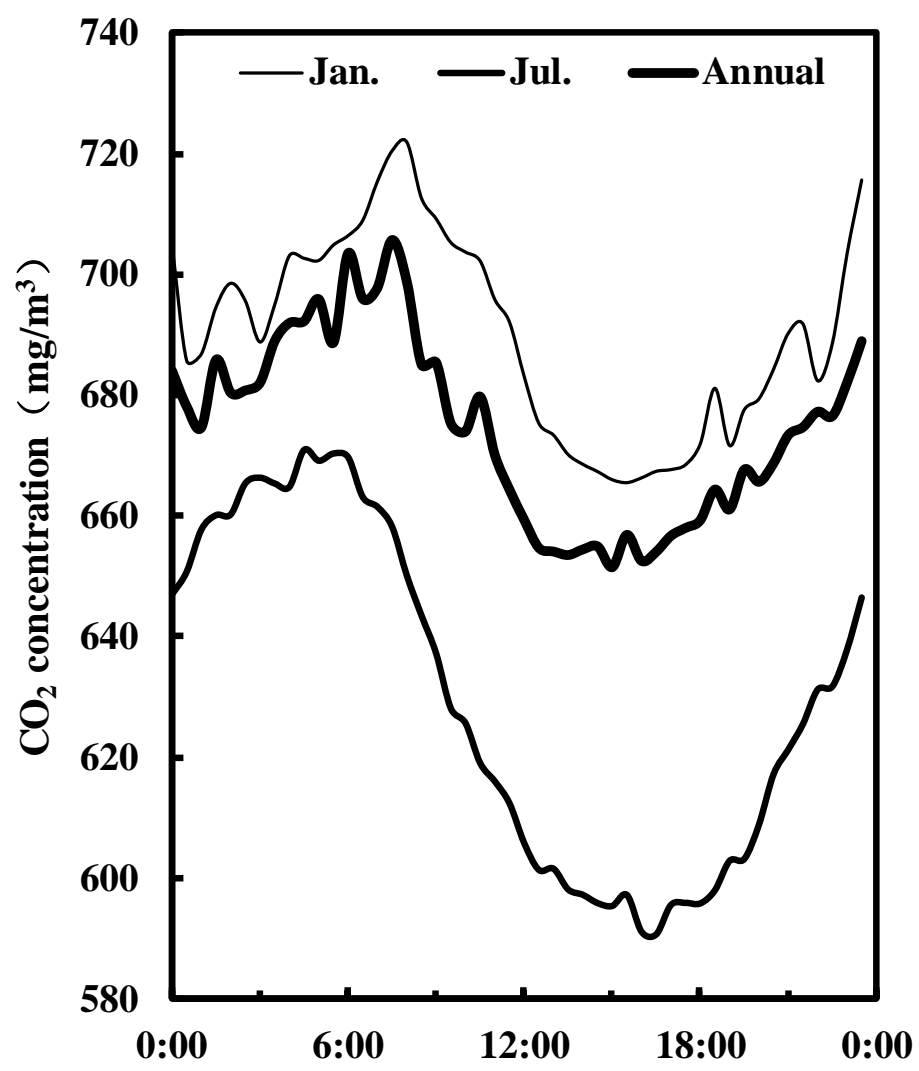

Figure 6. Annual diurnal variation process of Jinhewan Wetland $\mathrm{CO}_{2}$ concentration

The seasonal variation characteristics of the $\mathrm{CO}_{2}$ concentration is analyzed based on its $6 \mathrm{~h}$ rolling average data (see Fig. 7). The average $\mathrm{CO}_{2}$ concentration during the observation period was $679.45 \mathrm{mg} / \mathrm{m}^{3}$. Among them, the average $\mathrm{CO}_{2}$ concentration during the vigorous growth period of vegetation was only $655.97 \mathrm{mg} / \mathrm{m}^{3}$, and the $\mathrm{CO}_{2}$ concentration was relatively stable, basically fluctuating within the range of 500$800 \mathrm{mg} / \mathrm{m}^{3}$; while the average value of $\mathrm{CO}_{2}$ concentration in other periods was $684.86 \mathrm{mg} / \mathrm{m}^{3}$, with intense fluctuation and a maximum of $2000 \mathrm{mg} / \mathrm{m}^{3}$. 


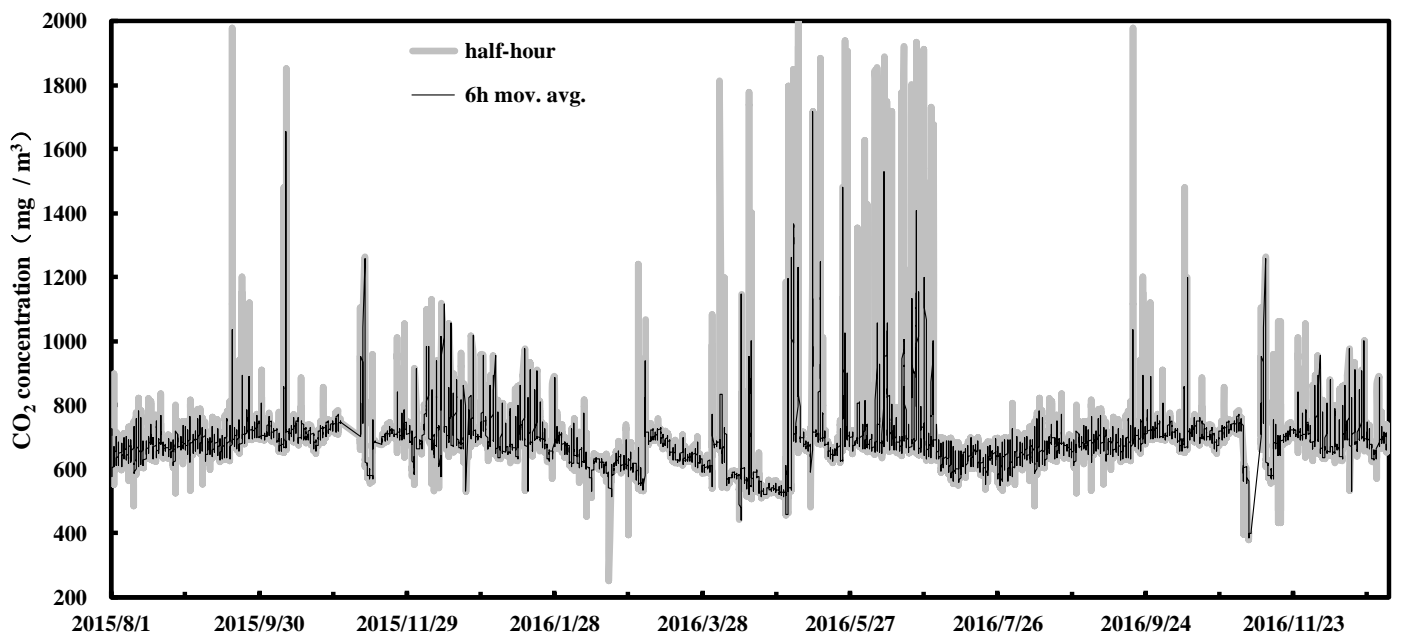

Figure 7. Annual change process of Jinhewan Wetland CO2 concentration during August 2015-December 2016

\section{Discussion and conclusion}

The material and energy exchange process on the ground-air interface of the cold zone wetland ecosystem in northeast China plays an important role in its climate change research and eco-protection. Jinhewan Wetland, as an example of Harbin's key ecological wetland for the protection and restoration of aquatic ecosystems, uses the EC flux measurement system to conduct long-term continuous flux observations. Based on the one-and-a-half year flux observations, this study initially analyzed the dynamic change characteristics of Jinhewan Wetland's water, heat, and $\mathrm{CO}_{2}$ fluxes.

The SHF, LHF and Bowen ratio of Jinhewan Wetland basically has the characteristics of single-peaked diurnal variation; in summer, LHF is generally higher than in the other three seasons due to the highest temperature and strongest evapotranspiration; in spring, SHF is usually the largest because summer vegetation is in the vigorous growing period when most of the net radiation is consumed by strong evapotranspiration of vegetation, so SHF is smaller in summer than in spring; in case of the same season, LHF is smaller than SHF in winter, and LHF is almost always greater than SHF in the other three seasons; the two has the biggest difference in summer.

The diurnal variations of $\mathrm{CO}_{2}$ flux and concentration show a single-valley character and a single-peak and single-valley character respectively. The annual average diurnal variation of flux shows that the daily maximum absorption rate of $\mathrm{CO}_{2}$ is only 0.13 $\mathrm{mg} /\left(\mathrm{m}^{2} \cdot \mathrm{s}\right)$, which is far less than the Panjin wetland and carbon sequestration has not been fully exerted. There may be two reasons. On the one hand, the Panjin Wetland has a warm temperate monsoon climate, where the temperate of Jinhewan Wetland in the mid-temperate zone is relatively cold. On the other hand, the Panjin Wetland meets the needs of the public for citizen activities by making small areas of land hardening based on natural plow fields and artificial paddy fields. While Jinhewan Wetland, with a higher degree of artificiality, takes into account the needs of the citizens for leisure and entertainment and their landscape functions, thus the green land area is relatively small and the vegetation coverage is low. In view of Jinhewan Wetland's weak carbon sink function, investment in vegetation construction can be increased and the potential for carbon sequestration in wetland ecosystems can be fully tapped. The annual change process of the flux is consistent with the vegetation growth trend, the more vigorous the 
vegetation growth, the greater the flux (absolute value), and the annual change process of the concentration is just the opposite. The dynamic change characteristics of Jinhewan Wetland's flux are similar to flux changes in forest, grassland, and farmland ecosystems (Song et al., 2004; Liu et al., 2006; Wang et al., 2009).

The preliminary analysis results show that Jinhewan Wetland has a large room for the improvement of water-heat cycle and carbon sink function, and can further promote its role in the water-heat cycle and carbon sink function by strengthening vegetation construction and expanding the green area. Many factors such as undulating terrain, unfavorable weather conditions will affect the accuracy of flux measurement results by using EC technique (Massman and Lee, 2002), and to some extent hinder the application of the EC technique. However, the study area is flat and the elevation difference is only $5 \mathrm{~m}$. During the monitoring period, the temperature in the area was between -30 and $30{ }^{\circ} \mathrm{C}$, and the highest monthly precipitation was $154 \mathrm{~mm}$, with no adverse weather such as extreme temperatures and precipitation. Therefore, the effects of topography and climate in this study can be ignored (Eda et al., 2016; Evadzi et al., 2017; Kuang et al., 2017; Liu, 2018; Meng et al., 2018).

The material and energy exchange process on the ground-air interface plays an important role in its climate change research and eco-protection. Jinhewan Wetland, as an example of Harbin's key ecological wetland for the protection and restoration of aquatic ecosystems, by conducting long-term continuous monitoring on it, using ground-based fixed-point observation data and combining large-scale remote-sensing data, it is possible to achieve scale conversion of flux data from ground-based observations to surface mean values, thereby providing technical support for regulating regional microclimates, preventing soil erosion and protecting ecological environment (Wani et al., 2018).

Acknowledgements. This work was supported by the Natural Science Foundation of China under Project No. 51409103, No. 51379079 and No. 51809093 and PhD Research Initiation Project of North China University of Water Resources and Electric Power No. 201904001.

\section{REFERENCES}

[1] Baldocchi, D. (2003): Assessing the eddy covariance technique for evaluating carbon dioxide exchange rates of ecosystems: past, present and future. - Global Change Biology 9: 479-492.

[2] Baldocchi, D., Finnigan, J., Wilson, K., et al. (2000): On measuring net ecosystem carbon exchange over tall vegetation on complex terrain. - Boundary-Layer Meteorology 96: 257-291.

[3] Baldocchi, D., Falge, E., Gu, L., et al. (2001): FLUXNET: a new tool to study the temporal and spatial variability of ecosystem scale carbon dioxide, water vapor and energy flux densities. - Bulletin of the American Meteorological Society 82: 2415-2434.

[4] Brix, H., Sorrell, B. K., Lorenzen, B. (2001): Are Phragmites-dominated wetlands a net source or net sink of greenhouse gases? - Aquatic Botany 69: 313-324.

[5] Cao, S., Cao, G., Feng, Q., et al. (2017): Alpine wetland ecosystem carbon sink and its controls at the Qinghai Lake. - Environmental Earth Sciences 76(5): 210.

[6] Chen, C., Cleverly, J., Zhang, L., et al. (2016): Modelling seasonal and inter-annual variations in carbon and water fluxes in an arid-zone acacia savanna woodland, 19812012. - Ecosystems 19(4): 625-644.

[7] Chen, G. Q. (1996): Marsh in Sanjiang Plain. - Science Press, Beijing, pp. 165-168. 
[8] Duman, T., Schäfer, K. V. R. (2018): Partitioning net ecosystem carbon exchange of native and invasive plant communities by vegetation cover in an urban tidal wetland in the New Jersey Meadowlands (USA). - Ecological Engineering 114: 16-24.

[9] Eda, M., Lu, P., Kikuchi, H., et al. (2016): Reevaluation of early holocene chicken domestication in northern China. - J Archaeol Sci 67: 25-31.

[10] Edwards, G. C., Dias, G. M., Thurtell, G. W., et al. (2001): Methane fluxes from a wetland using the flux-gradient technique. The measurement of methane flux from a natural wetland pond and adjacent vegetated wetlands using a TDL-based flux-gradient technique. - Water Air and Soil Pollution 1: 447-454.

[11] Evadzi, P. I. K., Zorita, E., Huenicke, B. (2017): Quantifying and predicting the contribution of sea-level rise to shoreline change in Ghana: information for coastal adaptation strategies. - J Coastal Res 33(6): 1283-1291.

[12] Finnigan, J. J., Clement R., Malhi Y., et al. (2003): A re-evaluation of long-term flux measurement techniques, Part I: averaging and coordinate rotation. - Boundary Layer Meteorology 107(1): 1-48

[13] Foken, T., Wichura, B. (1996): Tools for quality assessment of surface based flux measurements. - Agricultural and Forest Meteorology 78: 83-105.

[14] Gao, J. Q., Xu, X. L., Zhang, F. (2008): Distribution characteristics of soil labile carbon along water table gradient of alpine wetland soils. - Journal of Soil and Water Conservation 22(3): 126-131.

[15] Guo, H. Q., Noormets, A., Zhao, B., et al. (2009): Tidal effects on net ecosystem exchange of carbon in an estuarine wetland. - Agricultural and Forest Meteorology 149: 1820-1828.

[16] Hao, Y. B., Cui, X. Y., Wang, Y. F., et al. (2011): Predominance of precipitation and temperature controls on ecosystem $\mathrm{CO} 2$ exchange in zoige alpine wetlands of Southwest China. - Wetlands 31(2): 413-422.

[17] He, Q. J., Zhou, G. S., Zhou, L. (2006): A comparative study of calculation methods for water and heat fluxes in Phragmites wetland in Panjin. - Journal of Meteorology and Environment 22(4): 35-41.

[18] Heinsch, F. A., Heilman, J. L., Mcinnes K. J., et al. (2004): Carbon dioxide exchange in a high marsh on the Texas Gulf Coast: effects of freshwater availability. - Agricultural and Forest Meteorology 125(1): 159-172.

[19] Hutley, L. B., Leuning, R., Beringer, J., et al. (2005): The utility of the eddy covariance techniques as a tool in carbon accounting: tropical savanna as a case study. - Australian Journal of Botany 53(7): 663-675.

[20] Kang, X., Hao, Y., Li, C., et al. (2011): Modeling impacts of climate change on carbon dynamics in a steppe ecosystem in Inner Mongolia, China. - Journal of Soils and Sediments 11(4): 562-576.

[21] Kayranli, B., Scholz, M., Mustafa, A., et al. (2010): Carbon storage and fluxes within freshwater wetlands: a critical review. - Wetlands 30: 111-124. https://doi.org/10.1007/s13157-009-0003-4.

[22] Kuang, Y., Qu, X., Yan, Y. (2017): Will higher traffic flow lead to more traffic conflicts? A crash surrogate metric based analysis. - Plos One 12(e01824588).

[23] Liu, C. M., Yu, H. N. (1997): Experimental Study on Moisture Movement in Soil-CropAtmosphere System. - Meteorological Press, Beijing, pp. 1-17.

[24] Liu, H. Z., Tu, G., Dong, W. J., et al. (2006): Diurnal variation and seasonal variation of water vapor and carbon dioxide fluxes at the ground-atmosphere interface in the semiarid region. - Chinese Journal of Atmospheric Sciences 30(1): 108-118.

[25] Liu, Z. (2018): Economic analysis of methanol production from coal/biomass upgrading. - Energ Source Part B 13(1): 66-71.

[26] Massman, W. J., Lee, X. (2002): Eddy covariance flux corrections and uncertainties in long term studies of carbon and energy exchanges. - Agricultural and Forest Meteorology 113: $121-144$. 
[27] Meng, L., Zhong, Y., Wang, Z., et al. (2018): Supergravity separation for Cu recovery and precious metal concentration from waste printed circuit boards. - ACS Sustain Chem Eng 6(1): 186-192.

[28] Nahlik, A. M., Fennessy, M. S. (2016): Carbon storage in US wetlands. - Nature Communications 7: 13835.

[29] Roland, B. S. (1991): An Introduction to Boundary Layer Meteorology. - China Meteorological Press, Beijing.

[30] Shen, Y., Liu, Y. F., Wang, Y. (2005): Application progress of eddy correlation method for calculating hydrothermal and $\mathrm{CO} 2$ fluxes at home and abroad. - Journal of Nanjing Institute of Meteorology 28(4): 560-566.

[31] Shoemaker, W. B., Anderson, F., Barr, J. G., et al. (2015): Carbon exchange between the atmosphere and subtropical forested cypress and pine wetlands. - Biogeosciences 12(8): 2285-2300.

[32] Smith, L. C., MacDonald, G. M., Velichko, A. A., et al. (2004): Siberian peatlands a net carbon sink and global methane source since the early Holocene. - Science 303(5656): 353-356.

[33] Song X., Liu, Y. F., Xu, X. F., et al. (2004): Observation and analysis of carbon, water, and heat fluxes in planted forests in the hilly region of the red earth during winter and spring. - Resource Science 26(3): 98-104

[34] Wang, C., Yuan, R. M., Luo, T., et al. (2013): Comparison of near-surface flux observations in urban and suburban areas of Nanjing. - Journal of China University of Science and Technology 43(2): 87-96.

[35] Wang, H. Y., Zhou, G. S. (2006): Long-term flux observation of reed ecosystem in Panjin wetland. - Journal of Meteorology and Environment 22(4): 18-24

[36] Wang, J. M. (1999): Land surface process experiments and ground-air interaction studies: from HEIFE to IMGRASS and GAME-Tibet/TIPEX. - Plateau Meteorology 18(3): 280294.

[37] Wang, J. M. (2012): Eddy-Related Flux Observation Instruction Manual. https://wenku.baidu.com/view/890bdd52f01dc281e53af0d3.html

[38] Wang, W. Z., Xu, Z. W., Liu, S. M., et al. (2009): Analysis of characteristics of water and heat flux in different underlying surfaces in the Heihe River Basin. - Advances in Earth Science 24(7): 714-723.

[39] Wani, S. A., Najar, G. R., Akhter, F. (2018): Characterization of available nutrients that influence pear productivity and quality in Jammu and Kashmir, India. - J Environ Biol 39(1): 37-41.

[40] Webb, E. K., Pearman, G. I., Lenning, R. (1980): Correction of flux measurements for density effects due to heat and water vapour transfer. - Quarterly Journal of the Royal Meteorological Society 106: 85-100. DOI: 10.1002/qj.49710644707.

[41] Wilczak, J. M., Oncley, S. P., Stage, S. A. (2001): Sonic anemometer tilt correction algorithms. - Boundary-Layer Meteorology 99(1): 127-150.

[42] Xu, Z. W., Liu, S. M., Gong, L. J., et al. (2008): Processing and quality evaluation of observational data of eddy covariance instrument. - Advances in Earth Science 23(4): 357-370.

[43] Yang, Q., Lyu, X. G. (1999): A preliminary study on the dynamic changes of soil respiration in the wetland ecosystem of the Sanjiang Plain. - Journal of Soil 30(6): 254256.

[44] Zheng, N. (2013): The Turbulence Theory Analysis of the sensible Heat Flux in Forest Ecosystems Accurately Measured by the Scintillation Method. - Chinese Academy of Forestry, Beijing. 